Action Plan 2000-2004. IUCN, Gland, Switzerland). Even so, although the problem of disease transfer may be getting worse (e.g. Jackson et al., 2014, Emu, 114, 283-289), the World Parrot Trust recently outlined its 'release to restore' plans for several species, sometimes to free confiscated wildcaught parrots in areas from which the species in question have disappeared, but sometimes to release birds that are expected eventually to unite with their wild counterparts.

An example is the proposed release of six Critically Endangered blue-throated macaws Ara glaucogularis into the species' only known area in Beni, Bolivia. World Parrot Trust's PsittaScene (May 2013, 10-11) argues that, because so few wild birds remain, the release will constitute a reintroduction, not a reinforcement (sensu IUCN/SSC, 2013, Guidelines for Reintroductions and Other Conservation Translocations, v. 1.o), because 'contact with any wild bird is unlikely to occur soon after release'. But, given that macaws are spiritedly long-distance travellers (e.g. Bonilla-Ruz et al., 2007, Wilson Journal of Ornithology, 119, 729-732), how small should this unlikelihood be? What constitutes 'soon'? Confiscated grey parrots Psittacus erithacus released at Lake Victoria were, within 3 months, 'regularly mixing and flying with a small group of wild birds' (PsittaScene August 2014, 13-14). If (1) some parrot diseases incubate for many months, (2) some healthy birds are life-long carriers, and (3) some cases escape detection however carefully screened, how confident can we be that releasing the macaws serves the best interests of the species?

When confiscated birds are involved the alternatives are far from pleasant: deployment to zoos for education, lifelong care at a centre, or-most depressingly-euthanasia (although this is illegal in Indonesia for threatened species). All the more reason, therefore, that any release programme must observe the highest levels of scrutiny for pathogens (Jakob-Hoff et al., 2014, Manual of Procedures for Wildlife Disease Risk Management. OIE, Paris, France), keeping birds in secure quarantine for $3^{-6}$ months and retesting them at least twice for different diseases according to circumstance. Without such rigour, can the risk posed by captive birds to any targeted wild population-especially if the only population-ever be acceptable?

Nigel J. Collar BirdLife International, Cambridge, UK E-mailnigel.collar@birdlife.org

Michael Lierz Clinic for Birds, Reptiles, Amphibians and Fish, Justus-Liebig-Universität Giessen, Germany

MARK R. Stanley PRICE WildCRU, University of Oxford, Oxford, UK

ROLAND Z. WIRTH ZGAP, Munich, Germany

\section{New evidence of dhole Cuon alpinus populations in north-west China}

As a happy consequence of snow leopard surveys being conducted by our teams across China, we are pleased to report important new evidence of populations of the dhole Cuon alpinus from two sites in north-west China. The first is from camera-trapping surveys in the Shulenan Mountain range in Yanchiwan National Nature Reserve on the northern edge of the Qinghai-Tibetan Plateau in Gansu Province. Here, on two occasions, we have recorded a single female with at least two pups. The first photographs, in May 2013, showed a female with two pups $<_{1}$ month old. The second set of photographs, in July 2013, showed a female with two older pups, perhaps 3 months old. The timing is consistent with these being the same individuals, as is the distance between the camera stations of $4.5 \mathrm{~km}$. However, as there were no distinguishing features visible, we were unable to determine conclusively whether these were the same individuals. Further photographs taken between January 2013 and May 2014 revealed dhole packs of at least five individuals within the Reserve. It is not possible to determine how many packs live in this area. Information about dholes has also been reported by local livestock herders and confirmed by local staff within the Reserve. These reports suggest two or more packs of up to 30 individuals live in this area. Photographs and reported sightings in Yanchiwan occurred at elevations of c. 2,500-4,000 m.

It was also recently brought to our attention that during 2011-2013 livestock herders and local government officials reported dholes in the vicinity of Taxkorgan Nature Reserve, in the Karakoram/Pamir Mountain region of Xinjiang Autonomous Region, on China's border with Pakistan, Tajikistan and Afghanistan. The accuracy of these reports has been confirmed, with herders able to distinguish between pictures of the dhole (referred to in Mandarin as chái: 烸) and the wolf (láng: 狼). Packs of 7-30 dholes were sighted on six occasions in areas to the east of Taxkurgan at c. 2,000-3,500 m. Nine incidences of livestock depredation by dholes were reported during this period, with sheep and yak being the targeted prey. Pack sizes associated with depredation events were reported to be between three and 'more than 20' individuals.

With as few as 2,500 mature individuals remaining in the wild, mostly in South and South-east Asia, and populations thought to be in decline, these new records of the dhole extend the known range for the species significantly. The existence of the population on the northern edge of the Qinghai-Tibetan Plateau had been suspected, although unconfirmed, since a reported sighting in 2003. There have been no recent records of dholes from the Karakorum/ Pamir region and so the new evidence is important. We are now undertaking more detailed surveys for this species 
in China and neighbouring countries, particularly focused in the Tien Shan and Pamir Mountain region.

PHILIP RIORDAN ${ }^{*} \dagger$ Department of Zoology, University of Oxford, South Parks Road, Oxford, UK

E-mail philip.riordan@zoo.ox.ac.uk

JUN WANG $\ddagger$ and KUN SHI ${ }^{*} \dagger$ The Wildlife Institute, Beijing Forestry University, Beijing, China

HONGYAN $F u$ and ZHU DabUXILIKE Yanchiwan National Nature Reserve, Subei County, Gansu Forestry Administration, China

Kebiao Zhu and XiaOHu Wang Kashi Wildlife Conservation and Management Division, Xinjiang Forestry Administration, China

${ }^{*}$ Also at: Wildlife Without Borders UK, Oxford, UK $\dagger$ Also at: The Wildlife Institute, Beijing Forestry University, Tsinghua-East, China

$¥$ Also at: Department of Biological Sciences, Manchester Metropolitan University, Manchester, UK

\section{Increasing concern over trade in bat souvenirs from South-east Asia}

Wildlife species are harvested and traded in many forms, including as souvenirs such as claws, ivory jewellery, marine shells and preserved specimens of insects and other small animals. During a visit to Vietnam's Ho Chi Minh City with South-east Asian bat researchers in December 2014 we encountered mounted specimens of bats alongside specimens of insects and other invertebrates for sale in souvenir shops. Although such trade is known in South-east Asia, one particular species, the woolly painted bat Kerivoula picta, stood out. K. picta is a distinctive orange-coloured bat with patches of black on the wing membrane. It occurs from South Asia, southern China and mainland South-east Asia to Sumatra, Java and the Moluccas, although there are few recent records for its eastern range. The asking price for a mounted specimen was c. USD 22, and one mounted with a tube-nosed bat (Murina sp.) was c. USD 21 (USD 14 after discussion) in another shop. Other mounted bat species for sale included pipistrelles (labelled 'Pipistrel') for c. USD 12 each, and fruit bats (Macroglossus sp.), labelled 'dog bats'. SJR has also observed many mounted bats, typically Tylonycteris sp., for sale in tourist markets in China.

The trade in bat specimens goes beyond tourist shops; a search on e-commerce site eBay, on 15 December 2014, using the term 'bat taxidermy' revealed mounted and osteological specimens of several South-east Asian bat species. These included frugivorous species labelled as Cynopterus sp., Macroglossus minimus and Rousettus leschenaultii, and the insectivorous species Hipposideros bicolor, Hipposideros larvatus, K. picta, Miniopterus medius, Otomops formosus, Pipistrellus javanicus, Rhinolophus lepidus, Scotophilus kuhlii and Tylonycteris robustula (although the identification of some specimens may be incorrect). Most sellers were based in the USA, and the others in Indonesia, Thailand and Vietnam. Apart from O. formosus, categorized as Data Deficient on the IUCN Red List, the other species are categorized as Least Concern. Although these sales do not involve threatened species, the legality of the procurement and sale of bat specimens is questionable. In Vietnam, for example, the Law on Forest Protection and Development (2004) affords protection to all wildlife species. It is illegal to hunt, transport, keep, advertize, sell or consume wildlife without a permit; we do not know if the souvenir suppliers and sellers have the necessary permits. One eBay seller based in Vietnam had sold 84 framed K. picta at the time of our search and still had available stock. The prices of $K$. picta specimens on eBay were USD 18.50169.20 , typically more expensive than those we observed in Vietnam. Other websites that retail mounted bats include Amazon, Etsy, Oddities Store and the Evolution Store.

The potential unsustainability of harvesting bats for the souvenir trade is of concern given that we know little of wild bat populations and offtakes. Bats are long-lived and slowly reproducing, with many species already declining and facing future threats as a result of habitat loss. For example, the range-restricted Kitti's hog-nosed bat Craseonycteris thonglongyai-the world's smallest mammal-was threatened by collection for the souvenir trade shortly after its description in 1974 (Hutson et al., 2001, Microchiropteran Bats: Global Status Survey and Conservation Action Plan, IUCN). Although the harvest of bats for bushmeat has been reviewed at a global scale (Mickleburgh et al., 2009, Oryx, 43, 217-234), almost nothing is known of the potential impacts of the souvenir trade on bats. We call for socio-ecological studies on this trade, especially in range countries, to understand the extent of exploitation and the commodity chain. This information is urgently needed to determine whether the trade is sustainable and whether interventions are necessary to curb the trade of such wildlife souvenirs.

We thank the Southeast Asian Bat Conservation Research Unit supported by the National Science Foundation under Grant No. 1051363.

Benjamin P.Y.-H. Lee and Matthew J. Struebig Durrell Institute of Conservation and Ecology, School of Anthropology and Conservation, University of Kent, Canterbury,UK. E-mail benjamin.lee@alumni.nus.edu.sg

STEPHEN J. ROSSITER School of Biological \& Chemical Sciences, Queen Mary University of London, London, UK

Tigga KIngston Department of Biological Sciences, Texas Tech University, Lubbock, Texas, USA 